\title{
Synthesis of Titanium Dioxide Nanoparticles Coated Sand
}

\author{
Rakhi M S ${ }^{1} \&$ Suresh Babu $\mathrm{G}^{2}$ \\ ${ }^{I} P G$ Student, Department of Energy and Environment, National Institute of Technology, Tiruchirappalli, India. \\ ${ }^{2}$ Assistant General Manager, Production, Kerala Minerals \& Metals Ltd., Kerala.
}

Copyright: @2021 Rakhi MS \& Suresh Babu G. This is an open access article distributed under the terms of the Creative Commons Attribution License, which permits unrestricted use, distribution, and reproduction in any medium, provided the original author and source are credited.

\section{ABSTRACT}

Heavy metals are the most hazardous pollutants present in industrial and domestic wastewater. Wastewater containing heavy metal ions is considered as one of the serious environmental problem. Among all water contaminants, heavy metal ions such as lead, cadmium, zinc, nickel and mercury have high toxic and non-biodegradable properties and can cause severe health problems in animals and human beings. Several conventional methods exist for the removal of heavy metal pollutants from wastewater. Among these techniques, the adsorption process has come to the forefront as one of the major techniques for heavy metal removal from water/wastewater. This paper presents synthesis of Titanium dioxide nanoparticles coated sand and the removal of heavy metals using titanium dioxide nanoparticles coated sand.This review also presents an overview of the importance of nanotechnology in removing heavy metals from water/wastewater.

Keywords: Adsorption, Heavy metals, Nanotechnology, Wastewater.

\section{Introduction}

Water is the most essential compound for the sustenance of any living creature. Water is having a significant impact in our life and culture, which has increased through the centuries. At the beginning of 2000, it was estimated that one-sixth of the global population (1.1 billion people) did not have improved water supply. When the human population increases to 8 billion by the year 2025, the demand for water also increases. The ethical right of all people to access water now and in the future is a challenge for the global community.

While water is a renewable resource, it is at the same time a finite resource. It is important to appreciate the fact that only 3 percent of the world ${ }^{\text {ees }}$ water is fresh and roughly one-third of it is accessible. The rest is very unevenly distributed and the available supplies are increasingly contaminated with wastes and pollution from industry, agriculture and households. Over the years, increasing population, growing industrialization, expanding agriculture and rising standards of living have pushed up the demand for water. Efforts have been made to collect water by building dams and reservoirs and creating ground water structures such as wells. Recycling and desalination of water are other options but cost involved is very high. However, there is a growing realization that there are limits to „finding more watere and in the long run, we need to know the amount of water we can reasonably expect to tap and also learn to use it more efficiently.

It is the human nature that we value things only when they are scarce or are in short supply. As such we appreciate the value of water once the rivers, reservoirs, ponds, wells, etc. run dry. Our water resources have now entered an era of scarcity. It is estimated that thirty years from now, approximately one-third of our population will suffer from chronic water shortages. The increasing demand on fresh water resources by our burgeoning population and diminishing quality of existing water resources because of pollution and the additional requirements of serving our spiraling industrial and agricultural growth have led to a situation where the consumption of water is rapidly increasing and the supply of fresh water remains more or less constant. It may be mentioned that the water 
available to us is the same as it was before but the population and the consequent demand for water has increased manifold. The consequences of scarcity will be more drastic in arid and semi-arid regions. Water shortage will also be felt in rapidly growing coastal regions and in big cities. Several cities are already, or will be, unable to cope with the demand of providing safe water and sanitation facilities to their inhabitants.

At the time of Independence, i.e., in 1947, the per capita availability of water in India was 6,008 cubic metres a year. It came down to 5,177 cubic metres a year in 1951 and to 1,820cubic metres a year in 2001. According to MidTerm Appraisal (MTA) of the 10th Plan, per capita availability of water is likely to fall down to 1,340 cubic metres in 2025 and 1,140 cubic metres in 2050. Wastewater from numerous industries such as paints and pigments, glass production, mining operations, metal plating, and battery manufacturing processes are known to contain contaminants such as heavy metal. These heavy metals in wastewater are not biodegradable and their existence in receiving lakes and streams causes bioaccumulation in living organisms, which leads to several health problems in animals, plants and human beings such as cancer, kidney failure, metabolic acidosis, oral ulcer, renal failure and damage for stomach of the rodent (El-Latif et al. 2013). As trace elements, some heavy metals (eg. Copper, zinc, selenium) are essential to maintain the metabolism of the human body. However, at higher concentration they can lead to poisoning (Singanan 2011). Gakwisiri et al. (2012) in his study reported that when zinc is present in less quantity in human"s body, it affects health considerably. Heavy metals can enter a water supply by industrial and consumer waste, or even from acidic rain breaking down soils and releasing heavy metals into streams, lakes, rivers and groundwater (Renge et al. 2012). Wastewater regulations were established to minimize human and environmental exposure to hazardous chemicals. This includes limits on the types and concentration of heavy metals that may be present in the discharged wastewater. The maximum contaminant limit (MCL) standards, for those heavy metals, proven by USEPA for wastewater are briefed below (Barakat 2011).

Table 1. Maximum contaminant limit of heavy metals

\begin{tabular}{|c|c|}
\hline Heavy metal & MCL $(\mathrm{mg} / \mathbf{L})$ \\
\hline Arsenic & 0.050 \\
\hline Cadmium & $\mathbf{0 . 0 1}$ \\
\hline Chromium & $\mathbf{0 . 0 5}$ \\
\hline Copper & $\mathbf{0 . 2 5}$ \\
\hline Nickel & $\mathbf{0 . 2 0}$ \\
\hline Zinc & $\mathbf{0 . 8 0}$ \\
\hline Lead & $\mathbf{0 . 0 0 6}$ \\
\hline Mercury & $\mathbf{0 . 0 0 0 0 3}$ \\
\hline
\end{tabular}

As a result of the degree of the problems caused by heavy metals pollution, removal of heavy metals from water/wastewater is important. Investigation into new and cheap methods of metal ions removal has been on the increase lately (Bernard et al. 2013, Kolodynska et al. 2014). The task of providing proper treatment facility for all polluting sources is difficult and also expensive, hence there is pressing demand for innovative technologies 
which are low cost, require low maintenance and are energy efficient. In order to detoxify heavy metals, various techniques like photocatalytical oxidation, chemical coagulants, electrochemical, bioremediation, ion-exchange resins, reverse osmosis, and adsorption have been employed. Bernard et al.(2013) conducted a study in which activated carbon produced from coconut shell (ACS) was used as adsorbent to remove $\mathrm{Cu} 2+, \mathrm{Fe} 2+, \mathrm{Zn} 2+$ and $\mathrm{Pb} 2+$ ions from electroplating industrial wastewater. Kinetic studies showed that pseudo-second-order reaction model best described the adsorption process.

Ahmed et al. (2012) studied the adsorption of heavy metals ions in continuous flow column having calcium carbonate as adsorbent at laboratory scale. The significant decrease in the concentration of all metal ions was observed after treatment. The initial concentration of metals such as $\mathrm{Zn} 2+, \mathrm{Cr} 3+, \mathrm{Pb} 2+, \mathrm{Cd} 2+, \mathrm{Cu} 2+$ and $\mathrm{Fe} 3+$ were 195, 156, 621, 342, 190 and $168 \mathrm{mg} / \mathrm{L}$ which were reduced up to the level of 0.0089, 0.1390, 0.3510, 0.0390, 0.0242 and $0.3397 \mathrm{mg} / \mathrm{L}$, respectively in treated samples. This significant removal of heavy metal ions indicates a remarkable efficiency of calcium carbonate as adsorbent.

The adsorption capacity of calcium carbonate was calculated, which were found $400-1500 \mathrm{mg} / \mathrm{g}$. Various biological treatments both aerobic and anaerobic can be used for heavy metal removal (Saidi 2010, Dhokpande et al. 2013). Sivaprakash et al. (2010) conducted batch and continuous sorption studies to remove copper (II) from aqueous solution using marine algae, Sargassum tenerrimum. Maximum copper uptake of $174.23 \mathrm{mg} / \mathrm{g}$ was observed according to the Langmuir model at an initial $\mathrm{pH}$ of 6 . The copper loaded biomass was eluted using 0.1 $\mathrm{M} \mathrm{HCl}$ and no damage to the biosorbent was caused. Effects of operating parameters such as bed height and flow rate were studied in a packed column and the metal uptake decreased with increase in flow rate.

Among the conventional methods, chemical precipitation and electrochemical treatment are less efficient, and also produce large quantity of sludge which is very difficult to treat. Ion exchange, membrane technologies and activated carbon adsorption process are extremely expensive when treating large amount of water/wastewater containing heavy metals in low concentration. So they cannot be used at large scale. This suggests the emerging need for technological advancements in water treatment to benefit people in many parts of the world.

\section{Materials and Methods}

\subsection{Preparation of Sand}

River sand of gradation between $2.34 \mathrm{~mm}$ and $0.86 \mathrm{~mm}$ was used. The sand was soaked in $8 \%$ nitric acid solution for 24 hours, rinsed with de-ionized water to $\mathrm{pH} 7$, dried at $105^{\circ} \mathrm{C}$ for 24 hours in preparation for surface coating.

\subsubsection{Synthesis of Titanium dioxide Nanoparticles Coated Sand}

Titanium dioxide nanoparticles coated sand was prepared by chemical reaction in shaker method using Titanium tetrachloride. The methods employed is discussed below:

\section{Chemical Reaction in Shaker}

$100 \mathrm{ml}$ of $1 \mathrm{M} \mathrm{TiCl}_{4}$ was used. The solution was stirred with a magnetic stirrer at $200 \mathrm{rpm}$ and $6 \mathrm{M} \mathrm{NaOH}$ solution was added for adjusting $\mathrm{pH}$ at 9.5 and mixed for 5 minutes. The mixed solution was introduced to $100 \mathrm{~g}$ sand in a 


\section{AJAST}

Asian Journal of Applied Science and Technology (AJAST)

Volume 5, Issue 1, Pages 72-81, January-March 2021

glass bottle $(300 \mathrm{ml})$ and was placed in a temperature-controlled shaker at $60^{\circ} \mathrm{C}$, then stirred at $200 \mathrm{rpm}$ for 24 hours. After that, the coated sand was dried in an oven at $105^{\circ} \mathrm{C}$ for 24 hours. Finally, the prepared sand particles were washed with de-ionized water for removing uncoated particles, dried at $60^{\circ} \mathrm{C}$ for 24 hours and used for future experiment.

\subsubsection{Synthesis of Titanium dioxide Coated sand}

Titanium dioxide coated sand was synthesized using $\mathrm{TiCl}_{3} \cdot 6 \mathrm{H}_{2} \mathrm{O}$. The method employed is discussed below:

Using $\mathrm{TiCl}_{3} 6 \mathrm{H}_{2} \mathrm{O}$

$1000 \mathrm{~g}$ sand was spread out to form a $3 \mathrm{~cm}$ thick layer in a plastic tray. A volume of $1000 \mathrm{ml}$ of $1 \mathrm{M} \mathrm{TiCl} 3 \cdot 6 \mathrm{H}_{2} \mathrm{O}$ was added to the tray. After 30 minutes of contact the excess solution was poured off and the sand was allowed to dry for 24 hours. The dried sand was transferred slowly into a 2 litre glass beaker containing $1000 \mathrm{ml}$ of $3 \mathrm{M}$ ammonium hydroxide and was allowed to soak for 10 minutes.

The excess liquid was poured off and the sand was air dried in the plastic tray with occasional stirring. The dried sand was rinsed vigorously with de-ionised water to remove loose precipitates, then air dried in the plastic tray. The coated sand was stored in plastic bottles at room temperature until used.

\section{Results and Discussions}

\subsection{Influent Characteristics of Wastewater}

The $\mathrm{pH}$, turbidity, alkalinity, total dissolved solids, lead, zinc and cadmium of the influent wastewater were determined and the values are reported in table 2. The lead and cadmium content were very low. So the influent sample was spiked with known concentration of lead and cadmium which matches with the concentration of lead and cadmium for wastewater as reported in previous studies.

Table 2. Influent characteristics of the sample

\begin{tabular}{|c|c|}
\hline Parameter & Value \\
\hline pH & $6.4-6.7$ \\
\hline Turbidity, NTU & $5.0-9.0$ \\
\hline Alkalinity, mg/l as CaCO 3 & $15.0-19.0$ \\
\hline Total Dissolved Solids, ppm & $24.1-26.9$ \\
\hline Lead, mg/l & 0.04 \\
\hline Zinc, mg/l & 0.93 \\
\hline Cadmium, mg/l & 0.04 \\
\hline
\end{tabular}

Table 2 shows the influent characteristics of waste water after spiking with known concentration of lead and cadmium. 
Table 3. Influent characteristics of the sample after spiking

\begin{tabular}{|c|c|}
\hline Parameter & Value \\
\hline pH & 6.7 \\
\hline Turbidity, NTU & 9.0 \\
\hline Alkalinity, $\mathbf{m g} / \mathbf{l}$ as $\mathrm{CaCO}_{3}$ & 16.0 \\
\hline Total Dissolved Solids, ppm & 26.9 \\
\hline Lead, $\mathbf{m g} / \mathbf{l}$ & 2.0 \\
\hline Zinc, $\mathbf{m g} / \mathbf{l}$ & 0.93 \\
\hline Cadmium, $\mathbf{m g} / \mathbf{l}$ & 0.8 \\
\hline
\end{tabular}

\subsection{Adsorption Isotherm}

Adsorption isotherm has been investigated for the removal of lead and cadmium by titanium di oxide nanoparticles coated sand synthesized by chemical reaction in shaker. Since the concentration of zinc was below detectable limit in all the samples collected during various time intervals, it is impossible to investigate the adsorption isotherm for the removal of zinc.

Adsorption isotherms are mathematical models that describe the distribution of the adsorbate species among liquid and adsorbent, based on a set of assumptions that are mainly related to the heterogeneity/homogeneity of adsorbents, the type of coverage and possibility of interaction between the adsorbate species. Adsorption data are usually described by adsorption isotherms, such as Langmuir and Freundlich. These isotherms relate metal uptake per unit mass of adsorbent, $\mathrm{q}_{\mathrm{e}}$, to the equilibrium adsorbate concentration in the bulk fluid phase $\mathrm{C}_{\mathrm{e}}$. The adsorption data is plotted to fit a linearized form of the isotherms and the correlation coefficient of the straight-line plot determines the most appropriate isotherm form. The Freundlich isotherm is defined as:

$$
\mathrm{x} / \mathrm{m}=\mathrm{K}_{\mathrm{f}} \mathrm{C}_{\mathrm{e}}{ }^{1 / \mathrm{n}}
$$

Where, $\mathrm{x} / \mathrm{m}$ is the mass of adsorbate per unit mass of adsorbent ( $\mathrm{mg}$ adsorbate/g adsorbent), $\mathrm{K}_{\mathrm{f}}$ is Freundlich capacity factor, and $1 / \mathrm{n}$ is the Freundlich intensity parameter. The constants can be determined by plotting $\log (\mathrm{x} / \mathrm{m})$ versus $\log C_{e}$, where $1 / n$ is the slope of the line and $\log K_{f}$ is the $y$-intercept.

$$
\log (\mathrm{x} / \mathrm{m})=\log \mathrm{K}_{\mathrm{f}}+(1 / \mathrm{n}) \log \mathrm{C}_{\mathrm{e}}
$$

The Langmuir isotherm is defined as:

$$
(\mathrm{x} / \mathrm{m})=\left(\mathrm{abC}_{\mathrm{e}}\right) /\left(1+\left(\mathrm{bC}_{\mathrm{e}}\right)\right)
$$

Where, $\mathrm{a}$ and $\mathrm{b}$ are empirical constants with , $\mathrm{a}^{\mathrm{ec}}$ representing the maximum monolayer adsorption capacity (mg adsorbate/g adsorbent). „„ec has units of $\mathrm{L} / \mathrm{mg}$. The constants are also determined by plotting $\mathrm{C}_{\mathrm{e}} /(\mathrm{x} / \mathrm{m})$ versus $\mathrm{C}_{\mathrm{e}}$ where $1 / a$ is the slope of the line and $1 /(a b)$ is the $y$-intercept. 


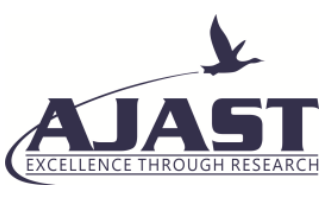

Asian Journal of Applied Science and Technology (AJAST)

Volume 5, Issue 1, Pages 72-81, January-March 2021

$$
\mathrm{C}_{\mathrm{e}} /(\mathrm{x} / \mathrm{m})=(1 / \mathrm{ab})+(1 / \mathrm{a}) \mathrm{C}_{\mathrm{e}}
$$

\subsection{Freundlich Adsorption Isotherm}

Freundlich adsorption isotherm is obtained by plotting $\log \mathrm{q}_{\mathrm{e}} \mathrm{vs} \log \mathrm{C}_{\mathrm{e}}$. For the adsorption of lead onto titanium dioxide nanoparticles coated sand synthesized by chemical reaction in shaker, the Freundlich adsorption isotherm is given in fig 1 . The value of correlation coefficient $\left(\mathrm{R}^{2}\right)$ is obtained as 0.7288 . The Freundlich adsorption isotherm for the adsorption of cadmium onto titanium dioxide nanoparticles coated sand is given in fig 2 . The value of correlation coefficient is obtained as 0.6875 .

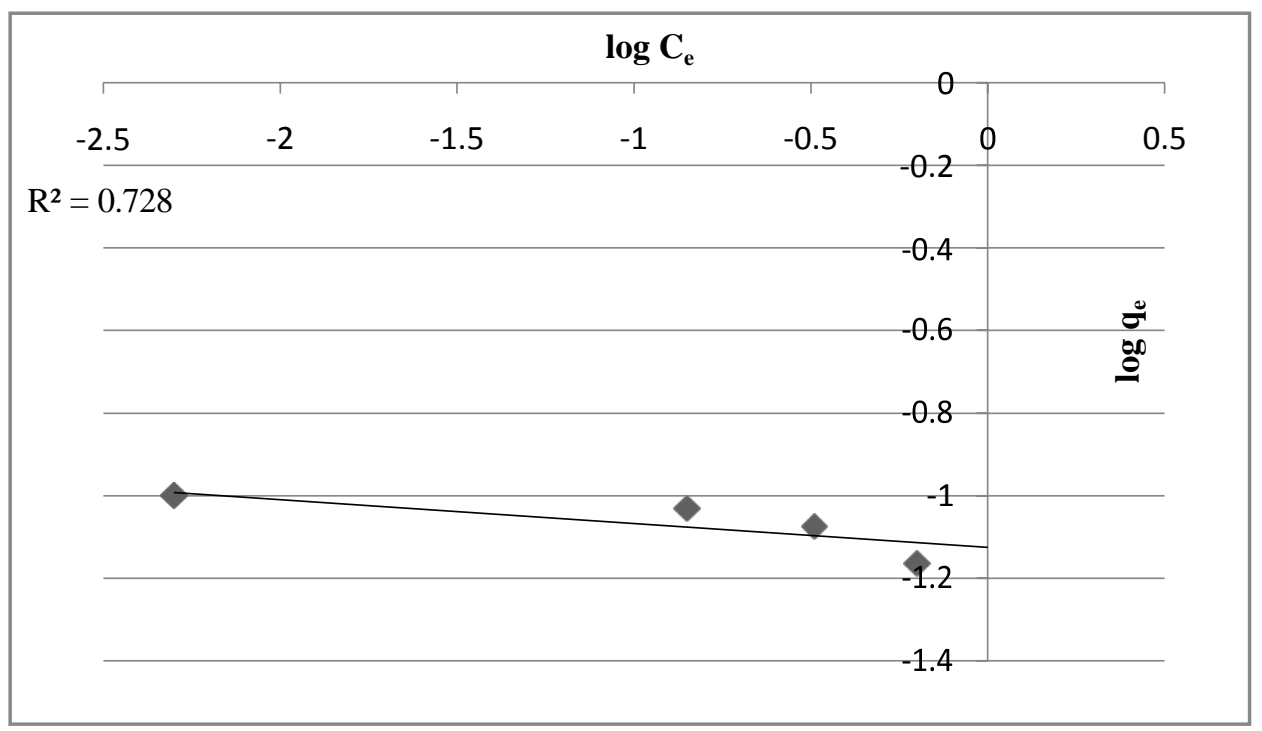

Fig.1. Freundlich adsorption isotherm of lead

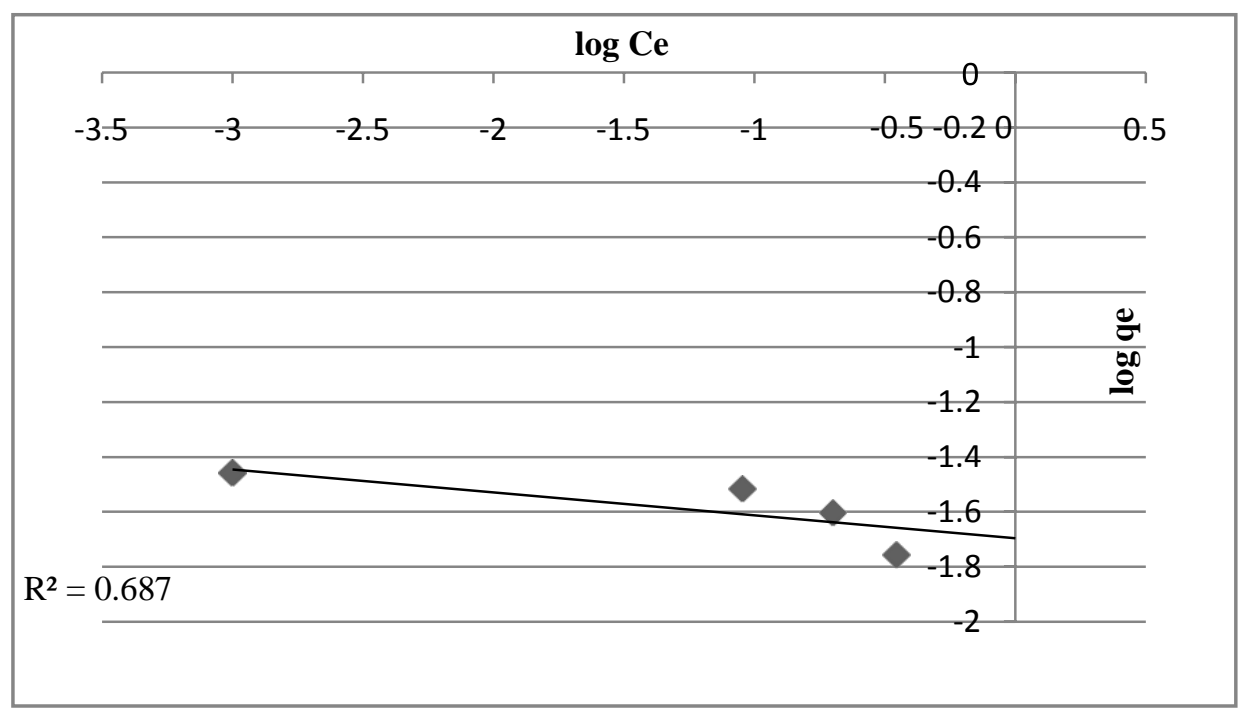

Fig.2. Freundlich adsorption isotherm of cadmium

\subsection{Langmuir Adsorption Isotherm}

Langmuir adsorption isotherm is obtained by plotting $\mathrm{C}_{\mathrm{e}} /(\mathrm{x} / \mathrm{m})$ vs $\mathrm{C}_{\mathrm{e}}$. For the adsorption of lead onto titanium dioxide nanoparticles coated sand synthesized by chemical reaction in shaker, the Langmuir isotherm is given in fig 3. The value of correlation coefficient is 0.991 . 


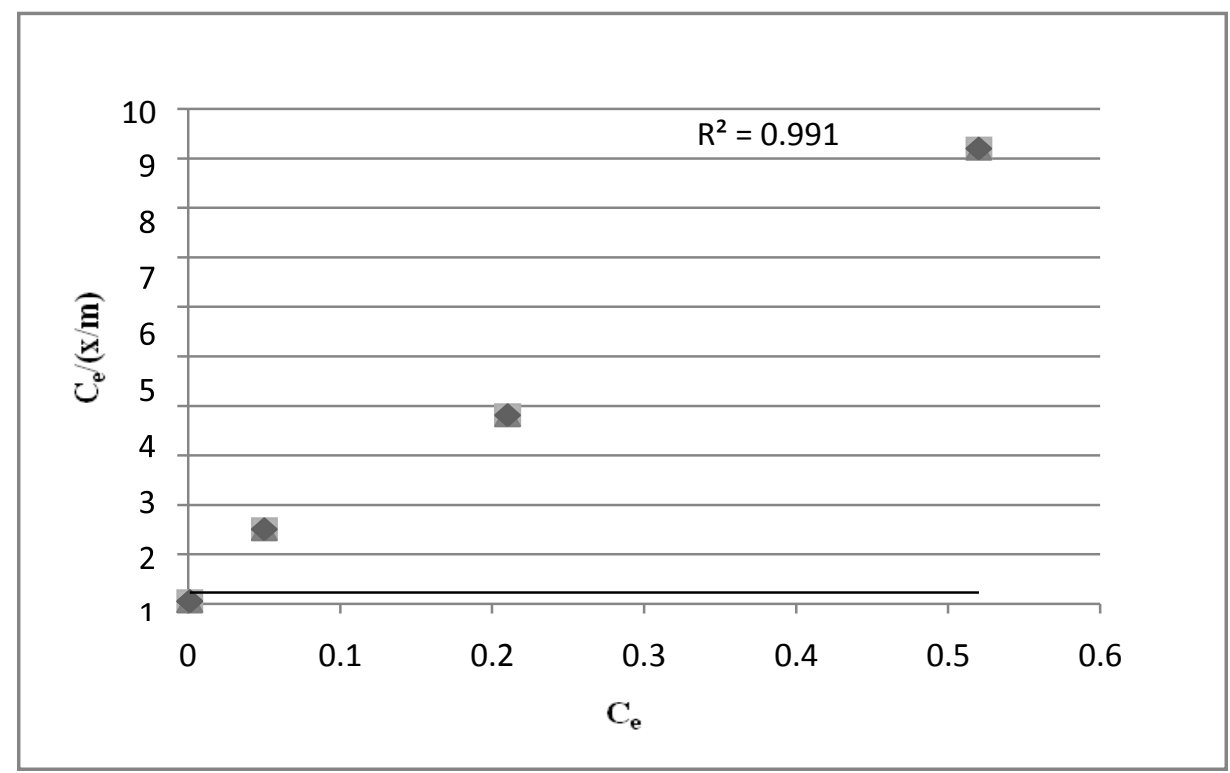

Fig.3. Langmuir adsorption isotherm of lead

The Langmuir isotherm for the adsorption of cadmium onto titanium dioxide nanoparticles coated sand is given in fig 4 . The value of correlation coefficient is 0.995

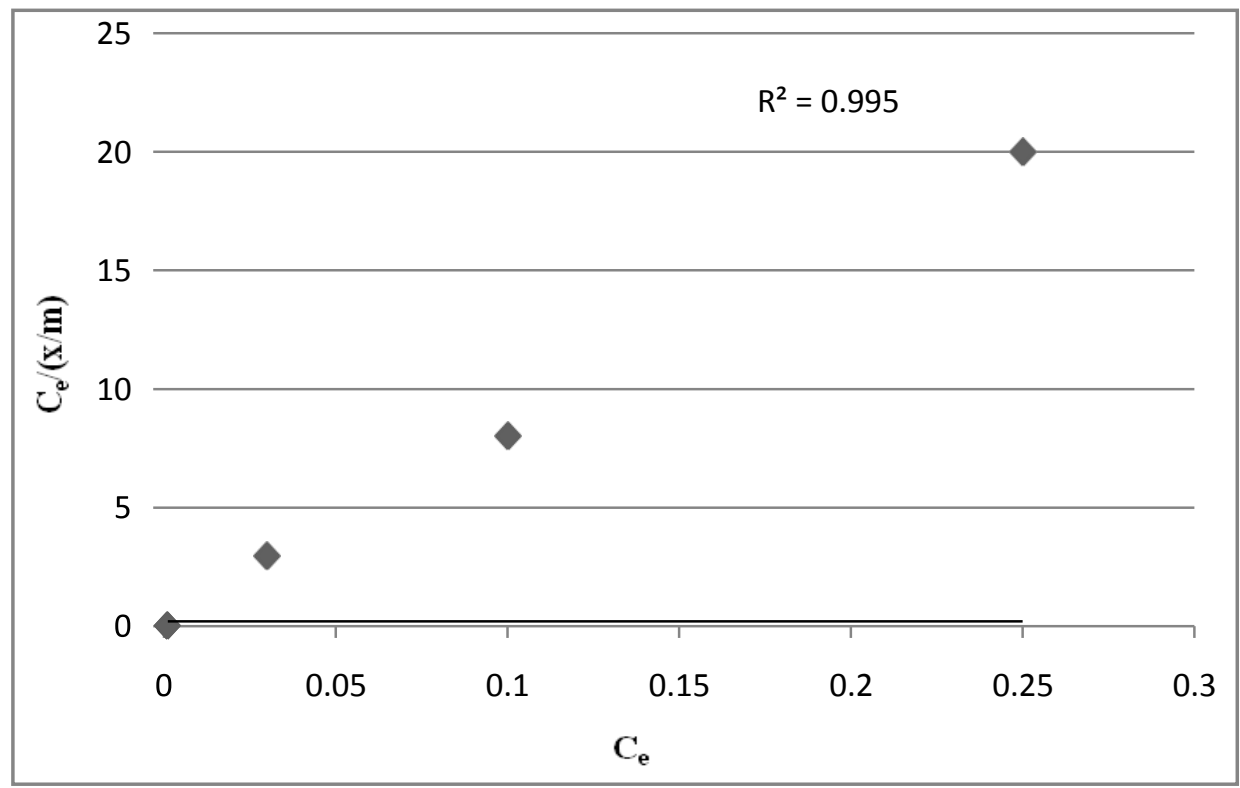

Fig.4. Langmuir adsorption isotherm of cadmium

Since the correlation coefficient values of Langmuir adsorption isotherm is greater than that for Freundlich adsorption isotherm, Langmuir isotherm is a better fit in this study. This suggests that there is homogeneous distribution of active sites on Titanium dioxide nanoparticles coated sand surface.

\subsection{Adsorption Kinetics}

In order to investigate the controlling mechanism of adsorption processes such as mass transfer and chemical reaction, the pseudo-first-order equation, pseudo-second order equation and intra-particle diffusion equation are applied to model the kinetics. 


\subsubsection{Pseudo-First Order Kinetics}

The pseudo-first-order rate equation is given as

$$
q_{t}=q_{e}\left(1-e^{-k, t}\right)
$$

Where, $\mathrm{q}_{\mathrm{t}}$ and $\mathrm{q}_{\mathrm{e}}$ are the amount adsorbed $(\mathrm{mg} / \mathrm{g}$ ) at time, $t$, and at equilibrium respectively and $\mathrm{k}$ is the rate constant of the pseudo-first-order adsorption process $\left(\mathrm{min}^{-1}\right)$. This equation is also known as Lagergen equation. Straight line plots of $\log \left(\mathrm{q}_{\mathrm{e}}-\mathrm{q}_{\mathrm{t}}\right)$ against time was used to determine the rate constant, $\mathrm{k}$.

\subsubsection{Pseudo-Second Order Kinetics}

The pseudo-second-order equation is expressed as

$$
\frac{t}{q_{t}}=\frac{1}{k_{2} q_{e}^{2}}+\frac{t}{q_{e}}
$$

Where, $\mathrm{q}_{\mathrm{t}}$ and $\mathrm{q}_{\mathrm{e}}$ are the amount adsorbed $(\mathrm{mg} / \mathrm{g}$ ) at time, $\mathrm{t}$, and at equilibrium respectively and $\mathrm{k}$ is the rate constant of the pseudo-second-order adsorption process. The plot $t / q_{t}$ versus $t$ should give a straight line if pseudo-second-order kinetics is applicable and $\mathrm{q}_{\mathrm{e}}$ and $\mathrm{k}$ can be determined from the slope and intercept of the plot, respectively.

On further investigation, it was found that the correlation coefficient values of pseudo second order kinetics is very much greater than pseudo first order kinetics. Therefore pseudo second order kinetics fits the study better than pseudo first order kinetics. The pseudo second order plot for the adsorption of lead onto titanium dioxide nanoparticles coated sand synthesized by chemical reaction in shaker is shown in fig 5. 1The value of correlation coefficient is 0.9713 .

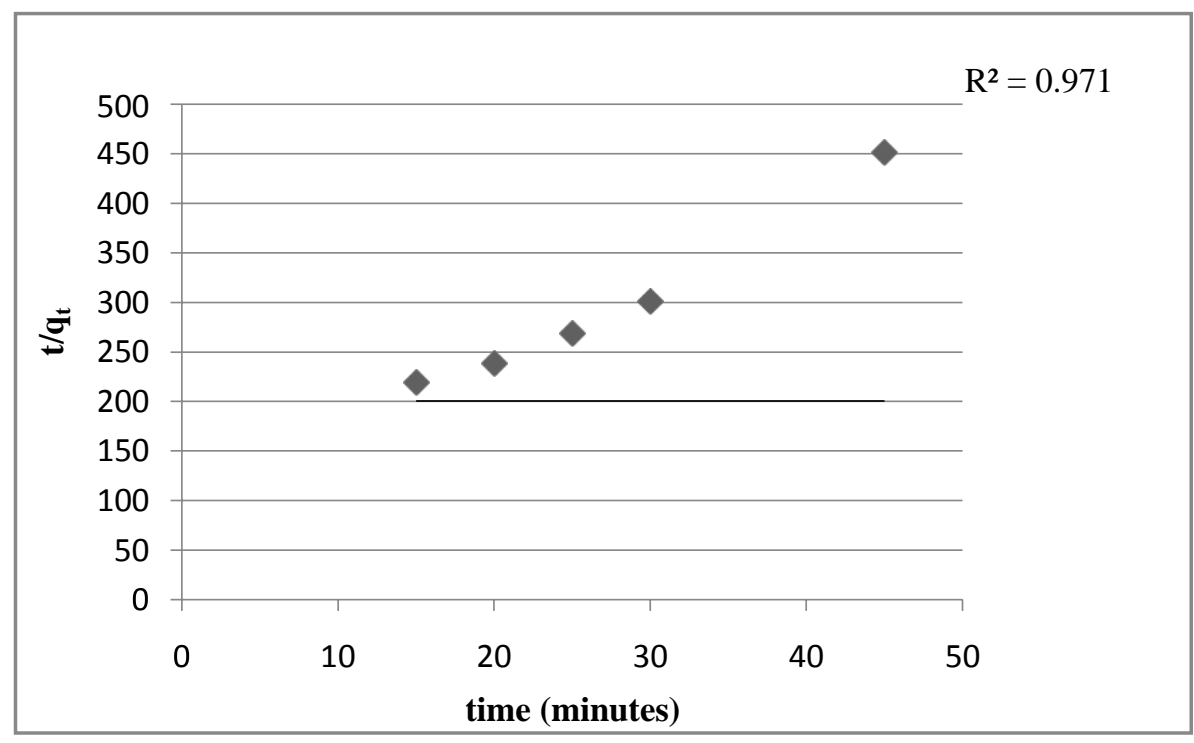

Fig.5. Pseudo second order model for lead adsorption

For the adsorption of cadmium onto titanium dioxide nanoparticles coated sand, the pseudo-second order kinetic model is given in fig 6 . The value of correlation coefficient is 0.8469 . 


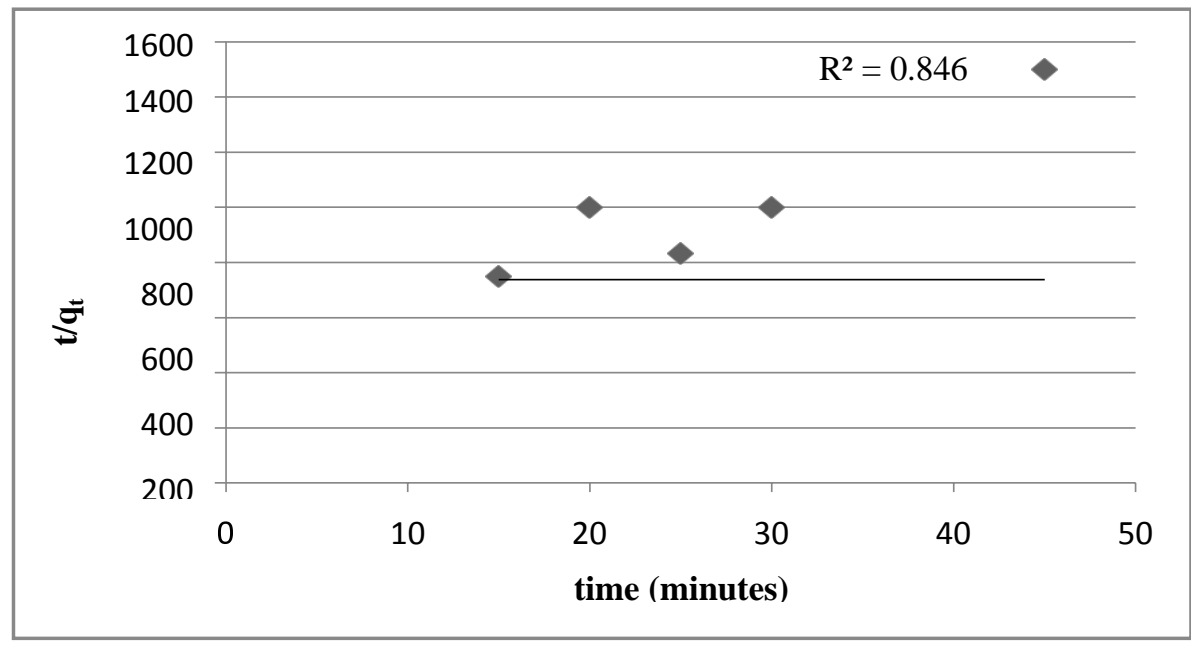

Fig.6. Pseudo second order model for cadmium adsorption

The values of correlation coefficient for pseudo second order kinetics is greater than pseudo first order kinetics So pseudo second order kinetics fits the model better than pseudo-first order kinetics. Since pseudo second order kinetic model fits the study, chemisorption may be the rate-limiting step. In chemisorption, the metal ions stick to the adsorbent surface by forming a chemical (usually covalent) bond and tend to find sites that maximize their coordination number with the surface.

\section{Conclusions}

Various studies have reported that Titanium dioxide nanoparticles is a good adsorption/filtration medium for the removal of heavy metals. The aim of the present study was to evaluate the performance of Titanium dioxide nanoparticles coated sand with respect to Titanium dioxide coated sand in removing heavy metals viz. lead, zinc and cadmium from wastewater. Titanium dioxide nanoparticles coated sand synthesized by chemical reaction in shaker gave the best results. It is seen that Langmuir isotherm fits the adsorption of lead, zinc and cadmium onto Titanium dioxide nanoparticles coated sand. So there is homogenous distribution of active sites onto Titanium dioxide nanoparticles coated sand surface. The adsorption follows pseudo-second order kinetics and chemisorption may be the rate limiting step. No leaching of titanium from the medium was found during the course of the experiment. The results of the study showed the increased efficiency of Titanium dioxide nanoparticles coated sand in removing lead, zinc and cadmium from wastewater with respect to Titanium dioxide coated sand. Thus, Titanium dioxide nanoparticles coated sand can be used as a sorptive filter media for use in simple, low cost water purification devices in developing countries for treatment of wastewater.

\section{Declarations}

\section{Source of Funding}

This research did not receive any specific grant from funding agencies in the public, commercial, or not-for-profit sectors.

\section{Competing Interests Statement}

The authors declare no competing financial, professional and personal interests. 


\section{Consent for publication}

We declare that we consented for the publication of this research work.

\section{Code availability}

The programming code that we have used for this research is available and authors are willing to share when it is required.

\section{References}

[1] Ahammed M.M and Chaudhury M, "Sand based Filtration/Adsorption Media", Journal of Water Supply Research and Technology - Aqua, Vol. 45, pp. 67-71, 1996.

[2] Bailey R.P, Bennet T, and Benjamin M.M, "Sorption onto and Recovery of Cr (VI) using Iron Oxide-Coated Sand", Water Science Technology, Vol. 26, pp. 1239-1244,1992.

[3] Lukasik J, Truesdail S, Shah D.O, and Farrah S.R, "Adsorption of Microorganisms to Sand \& Diatomaceous Earth Particles Coated with Metallic Hydroxides”, Kona, Vol. 14, pp. 87-91,1996.

[4] Lukasik J, Cheng Y, Lu F, Tamplin M, and Farrah S.R, "Removal of Microorganisms from Water by Columns Containing Sand Coated with Ferric and Aluminium Hydroxides”, Water Research, Vol.33, pp. 769-777,1999.

[5] Theis T.L, Iyer R, and Ellis S.K, "Evaluating a New Granular Iron Oxide for Removing Lead from Drinking Water", Journal of American Water Works Association, Vol. 84, pp. 101-105,1992.

[6] Liu, Sansalone J.J, and Cartledge F.K, "Comparison of Sorptive Filter Media for Treatment of Metals in Runoff”, Journal of Environmental Engineering, Vol. 131, pp. 1178-1186, 2005.

[7] Cheng Z, Tan A.L.K, Tao Y, Shan D, Ting K.E, and Yin X.J, "Synthesis and Characterization of Iron Oxide Nanoparticles and Applications in the Removal of Heavy Metals from Industrial Wastewater", International Journal of Photoenergy, Vol. 2012, pp. 1-5, 2012.

[8] Zafour H.Z and Fernane F, "Heavy Metals Removal by Combining the Magnetic Properties of Iron Oxide with Adsorptive Properties of Double Scalled Carbon Nanotubes", Digital Proceeding of THE ICOESTee, 2013, Cappadocia, pp. 511-517, 2013.

[9] Palanisamy K.L, Devabharathi V, and Sundaram N.M, "The utility of Magnetic Iron Oxide Nanoparticles Stabilized by Carrier Oils in Removal of Heavy Metals from Wastewater", International Journal of Research in Applied, Natural and Social Sciences, Vol. 1, No 4, pp. 15-22, 2013. 